\title{
Língua, sujeito e identidade: algumas problematizações sobre a (des)constituição dos sujeitos-aprendentes no processo de ensino- aprendizagem de uma língua estrangeira*
}

\section{Language, identity and subject: a discussion on the (un)constitution of subject-learners in the process of foreign language teaching and learning}

Resumo: Este trabalho tem por objetivo, a partir da discursividade instaurada no episódio "Cidadania dupla" (Duel Citizenship) do seriado americano "Como eu conheci sua mãe" (How I met your mother) da grande rede de televisão estadunidense Columbia Broadcasting System (CBS), exibido no dia 19 de outubro de 2009, apresentar uma discussão de cunho mais teórico sobre os conflitos e embates nos espaços de ensino-aprendizagem de uma língua estrangeira. Tem-se por escopo problematizar que possivelmente os malogros que enfrentamos em uma sala de aula de língua estrangeira, antes de ser uma questão eminentemente metodológica e de escolhas didáticas, é uma questão que perpassa a (des)constituição subjetiva dos alunos frente à língua aprendida e ensinada. Uma questão marcada por conflitos e embates que merece algumas considerações. Para tanto, inscrito nos espaços analíticos da Linguística Aplicada, embasado nos pressupostos da teoria discursiva pecheutiana, nos estudos bakhtinianos acerca de língua e sujeito, e nas problematizações pós-culturalistas de identidade (HALL, 2006; BAUMAN, 2005), empreende-se ao propósito, observando o tripé língua, sujeito e identidade, enquanto um espaço confluente no processo de ensino e aprendizagem de uma LE, em cujo ínterim se estabelecem relações de (des)identificações, produzindo subjetividades.

Palavras-chave: língua estrangeira; língua materna; sujeito; identidade; ensino-aprendizagem

\begin{abstract}
This paper aims to present a theoretical discussion of the conflicts and confrontations in the area of foreign language teaching and learning, based on the discursivity established in the episode "Duel Citizenship" from the American series "How I Met Your Mother", showed by Columbia

\footnotetext{
* Este trabalho, filiado ao campo teórico da Linguística Aplicada, resulta de uma pesquisa de área complementar, em nível doutoral, realizada no Programa de Pós-Graduação em Estudos Linguísticos do Instituto de Letras e Linguística da Universidade Federal de Uberlândia, sob a orientação da Profa. Dra. Maria de Fátima Fonseca Guilherme de Castro.

${ }^{* *}$ Doutorando em Estudos Linguísticos na Universidade Federal de Uberlândia e atualmente cursando períodosanduíche na Université Paris 13 - Villetaneuse, como o apoio da CAPES. Mestre em Linguística e Linguística Aplicada pela Universidade Federal de Uberlândia e professor de Língua Inglesa no Centro de Línguas da Universidade Federal de Goiás - Câmpus Catalão. É membro integrante do Laboratório de Estudos Polifônicos (LEP) da Universidade Federal de Uberlândia e pesquisador vinculado ao Grupo de Estudos e Pesquisas em História do Português (GEPHPOR) da Universidade Federal de Goiás - Câmpus Catalão. E-mail: ismfero@gmail.com
} 
Broadcasting System (CBS) on October 19, 2009. The purpose is to analyze failures which we face in a foreign language classroom, showing that before being eminently a matter of methodological and didactic choices, they are a question which permeates the (non)subjective constitution of students facing the language learned and taught, being also a question of conflicts and confrontations that deserves some consideration. Therefore, within the analytic spaces of Applied Linguistics, based on discursive pecheutian theory's assumptions and on Bakhtin's studies about language and subject, as well as on the post-culturalist discussion concerning identity (HALL 2006; BAUMAN, 2005), this work intends to observe the tripod language, subject and identity, as a confluent space in the foreign language teaching and learning processes, in which relations of (un)identifications are established, producing subjectivities.

Keywords: foreign language; mother tongue; subject; identity; teaching-learning

\section{Introdução}

Há muito tempo, uma considerável parte de professores de língua estrangeira (LE) e pesquisadores da Linguística Aplicada (LA) demandam com porfia métodos e atividades prescritivas no sentido de tornar o processo de ensino-aprendizagem de uma LE mais profícuo e, portanto, promover aos alunos a fluência e aptidão para as quatro principais habilidades comunicativas, quer sejam falar, ouvir, ler e escrever.

Continuamente, buscou-se e ainda búsca-se o desenvolvimento de um rol de tarefas ou de materiais didáticos que possam ser aplicados, por exemplo, a quem está aprendendo a língua inglesa (LI) em qualquer parte do mundo. Prova disso, são os inúmeros livros didáticos e de apoio $^{1}$ (livros-texto, paradidáticos, CDs de áudio, CD-ROMs, cassetes, fitas de vídeo e outros) e manuais de atividades (worksheets, testes, jogos, exercícios e diversos recursos audiovisuais e de multimídia) que são publicados por editoras internacionais, especializadas no ensino de línguas estrangeiras.

\footnotetext{
${ }^{1}$ Pode-se, apenas a caráter ilustrativo, mencionar, entre vários outros materiais de suporte ao ensino de língua inglesa, a coleção didática, publicada pela Cambridge University Press e adotada em várias partes do mundo, Interchange, que configura, conforme se anuncia em sua apresentação, "a série para adultos e jovens aprendizes de inglês mais bem sucedida no mundo. Escrita em inglês americano, o curso demonstra o fato do inglês ser a principal língua da comunicação internacional e não estar limitado a nenhum país, região ou cultura. (Minha tradução para "the world's most successful series for adults and young adult learners of English. Written in American English, the course reflects the fact that English is the major language of international communication and is not limited to any one country, region, or culture" (RICHARDS; HULL; PROCTOR, 2005, p. viii).
} 
Professores sempre perquirem por atividades ${ }^{2}$ que tornem suas aulas mais dinâmicas e que façam seus alunos adquirirem uma segunda língua de forma eficaz e sem conflitos e/ou dificuldades. Obstinadamente, esperam-se receitas didáticas e instruções metodológicas que possam ser seguidas à revelia de elementos quer de ordens individuais, socioespaciais, quer histórico-culturais, para citar algumas. Mesmo que muito se fale em cultura local, saber local ${ }^{3}$, currículo educacional sob o crivo de balizas regionais, idiossincrasias discentes, ainda permanecem a homogeneidade, a elisão de diferenças, 0 apagamento de fronteiras, consequências próprias da globalização e da mundialização sociocultural, aos moldes do material, citado na nota um, que tem a pretensão de ser um material único, invariável e uma metodologia eficaz para o ensino da língua inglesa em qualquer parte do mundo, desvinculandoa de um espaço e cultura que lhe são imanentes.

Comumente, é apresentado aos alunos um idioma único, estável, sistêmico e invariável. Aprende-se, por exemplo, o inglês, no máximo, o inglês americano ou o inglês britânico, chegando esta a ser a dessemelhança mais precípua que se pode estabelecer e dizer aos aprendentes $^{4}$ da língua inglesa e, por isso, eu destacar a homogeneização e a obliteração de diferenças que ainda perpassam o contexto de ensino e aprendizagem de uma LE.

Para o alcance da aprendizagem de uma segunda língua ${ }^{5}$, parece sobrepujar a ideia consensual, resultado daquela perene busca metodológica, de que se deve sempre, nas aulas de

\footnotetext{
${ }^{2}$ Refiro-me ao termo atividades porque grande parte dos professores de LE se preocupa mais com atividades, tarefas, exercícios, técnicas que podem ser aplicados, do que com qual abordagem metodológica (gramáticatradução, método direto, audiolingual, comunicativa entre outras) poderá suportar atividades que, observando aspectos socioculturais e idiossincráticos de sua sala de aula, empreenderá no seu dia a dia de ensino. Posso parecer incisivo neste posicionamento, porque muito se fala em modelos, exemplos de atividades, livro didático enquanto guia que deve ser adaptado ao contexto educacional de cada espaço sociocultural. Porém, na prática, o que se pode observar, na maioria das vezes, é a obediência absoluta às instruções que trazem os manuais didáticos ou de apoio, não existindo, com efeito, adaptações/supressões/alterações dos exercícios apresentados.

${ }^{3}$ Conforme Canagarajah (2002).

${ }^{4}$ Aprendente ou sujeito-aprendente será entendido neste trabalho a partir da perspectiva de Santos (2006), que, estabelecendo uma diferença com aprendiz, concebe o aprendente como aquele sujeito que, por meio de uma dinâmica enunciativa, a partir de um lugar discursivo em dado um dispositivo pedagógico, não estabelece uma relação transferencial per si com o professor, mas uma relação interativo-comutativa. Portanto, mais que um aprendiz, sujeito carente de saberes cujos vácuos e lacunas de formação precisam ser preenchidos pelo conhecimento de um sujeito-ensinador, e uma vez preenchidos, efetivou-se e encerrou-se o processo de ensinoaprendizagem para o início de um outro, o aprendente está em constante formação e não ocupa um lugar de passividade na construção/apreensão de saberes. Antes, inscreve-se conjuntamente ao professor, em uma relação dinâmico-colaborativa, no perene e infindo processo de formação, (de)construindo práticas de conhecimentos e instaurando discursividades no, pelos e com os saberes.

${ }^{5}$ Língua estrangeira e segunda língua serão tomados ao longo deste trabalho como termos sinônimos, em que ambos concernirão a processos filiatórios e identificatórios com uma língua outra que não aquela na qual sujeitos construíram sua consciência e identidade(s) na relação sígnico-ideológica de convivência e experiência desde seu nascimento.
} 
uma língua estrangeira, simular situações reais de comunicação em que o idioma a ser aprendido seja apresentado aos alunos na voz de nativos. Daí se insistir no uso de filmes, seriados, músicas, documentários, noticiários pelos professores em sala de aula, e estes sempre procurarem por atividades que tenham por base as lyrics ou scripts desses gêneros discursivos ${ }^{6}$, que porão os alunos em contato real com a língua, além de proporcionarem momentos de descontração e ludismo.

Uma consequência desse legado instrucional de caráter didático-metodológico é a proliferação de sítios eletrônicos na internet, que dispõem de atividades com músicas e filmes para serem acessadas e usadas pelos professores; e inúmeras publicações de cadernos de worksheet e atividades lúdicas quem têm por base letras musicais e roteiros fílmicos.

Sendo assim, promove-se o largo uso desses recursos nas aulas de LE, possibilitando o contato dos alunos com situações sincrônicas de uso real da língua, com a prosódia linguística em interações sociais.

Não obstante, a simulação de situações comunicativas (encenação de diálogos, dramatização de conversações, para citar duas) e o emprego desses recursos em sala de aula, que pretende colocar os alunos frente ao uso real da língua que estão aprendendo, fracassos e o não alcance de objetivos ainda se ressaltam, como também “o não consigo fazê-los aprender" comina os escopos educativos dos professores.

Será meramente uma imprecisão metodológica dos recursos utilizados? Será um simples equívoco na escolha dos materiais ou da atividade que se propôs a realizar? Será apenas uma questão afetiva dos alunos que não se afinou com o alvitre do professor?

E vou mais além, por que ainda existem tantos fracassos e uma alta taxa de insucesso no campo da aprendizagem de línguas estrangeiras? Por que os resultados dessa incessante busca por materiais e aportes metodológicos, que renderam e rendem várias pesquisas em nível de doutorado e mestrado e publicações de livros e artigos, como também a copiosa elaboração de séries didáticas, ainda não conseguiram solucionar, ou ao menos amenizar,

\footnotetext{
${ }^{6}$ Concebido aqui, no crivo dos pressupostos teóricos de Bakhtin (1997), como as formas comunicativas verbosocioideológicas relativamente estáveis produzidas nas diversas esferas da atividade humana que produzem significações, por meio da acentuação valorativa e conteúdos temáticos, e da ressumação de marcas linguísticas, evidenciadas pelo estilo e pela forma composicional dos enunciados que compõem tais formas comunicativas.
} 
significantemente, os malogros de se aprender uma LE, tanto em contextos de escolas de idiomas quanto de escolas regulares de ensino ${ }^{7}$ ?

Ao perscrutar os meandros dos espaços teórico-metodológicos imanentes ao processo de ensino-aprendizagem de línguas estrangeiras, posso aventar que as sinuosidades e emaranhados conceptuais, constitutivos desses espaços, acenam que o óbice, enleador desse processo, antes de ser precipuamente uma questão didático-metodológica, é uma questão confluída no tripé língua, sujeito e identidade. É uma questão de (des)identificações perpassada por construções identitárias. É uma relação de conflito entre a língua materna (LM) e a língua estrangeira, produzindo efeitos de denegação e/ou reconhecimento no idioma do outro, estranho que não o meu familiar.

Assim o avento, porque, mais do que a forma como eu ensino uma LE, é o modo como eu, professor, vejo-me nessa língua, e a maneira como permito aos alunos se verem nela e por ela. Como eu coloco a língua perante os alunos e como os coloco perante ela. É, portanto, uma questão de constituição, de construção de um eu no viés do outro.

Nesse sentido, alvitrarei uma discussão cujo mote propulsor será a discursividade instaurada em um episódio do seriado americano "Como eu conheci sua mãe" (How I met your mother), uma comédia de situações do cotidiano $^{8}$ da grande rede de televisão estadunidense Columbia Broadcasting System (CBS). É uma série criada por Carter Bays e Craig Thomas, que estreou no dia 19 de setembro de 2005 e que gira em torno da vida de cinco amigos, Ted Mosby, Marshall Eriksen, Lily Aldrin, Barney Stinson e Robin Scherbatsky.

De grande sucesso, tanto nos Estados Unidos quanto no Brasil, a trama, já estando em sua oitava temporada, é narrada por Ted Mosby e começa no ano de 2030, quando ele senta o

\footnotetext{
${ }^{7}$ Talvez se possa indagar o porquê de aludir a esses dois contextos díspares de naturezas constitutivas imiscíveis. $\mathrm{Eu}$ os trouxe porque, tanto em um quanto em outro, a taxa de fracasso é alta. Em escolas regulares de ensino, os alunos têm cerca de sete anos de inglês, mas não conseguem terminar o Ensino Médio dominando minimamente as duas habilidades comunicativas que os PCNs (BRASIL, 1998) e OCEMs (BRASIL, 2006) prerrogam: ler e escrever com fluência. Em escolas de idiomas, são poucos os alunos que chegam às turmas de nível avançado, sendo raro encontrarmos classes com mais de cinco alunos. E o que dizer do alto índice de evasão que existe entre os que procuram essas escolas? Será somente uma questão de condições aquisitivo-monetárias? Acredito que não, pois já trabalhei em institutos de idiomas e sempre mantenho contato com professores e alunos que trabalham e estudam nesse ambiente educacional, e muitas das desistências têm sido decorrentes do "não conseguir aprender". Além disso, não são muitas as pessoas que terminam um curso de LE com um bom conhecimento de forma a ler um livro, assistir a um filme, seguir um diálogo entre "falantes nativos", sem dificuldades.

${ }^{8}$ Advindo de sitcom, abreviação de situation comedy, que se refere a séries televisivas em que personagens são prosaicas e as tramas consistem em uma ou mais histórias de humor, encenadas em ambientes comuns como família, grupo de amigos, local de trabalho, para citar alguns. Geralmente, são gravadas defronte a uma plateia ao vivo e caracterizadas pelos "sacos de risadas" (laugh tracks), a exemplo da antiga produção brasileira "Escolinha do Professor Raimundo" e da série "Toma lá dá cá", exibida há três anos pela Rede Globo.
} 
seu casal de filhos adolescentes no sofá para contar a história de como conheceu a mãe deles. Desde então, em uma digressão temporal, acompanham-se as muitas histórias de amizade, conquistas, festas, cervejas e diversão, ambientadas em Nova York, histórias essas que têm por cerne as peripécias amorosas de se encontrar alguém para dividir a vida.

Tomarei por base o quinto episódio da quinta temporada, intitulado "Cidadania dupla" (Duel Citizenship) e exibido no dia 19 de outubro de 2009, no qual Ted propõe uma viagem até Chicago com Marshall, de mais ou menos 22 horas de duração, só para comerem pizza mal assada no Gazzola, um lugar que frequentavam no tempo de universidade. Concomitantemente, Barney ensinará Robin, a amiga canadense do grupo, a ser uma verdadeira americana e a conseguir aprovação no teste de cidadania (citizenship test que de fato existe e é aplicado pelo U.S. Citizenship and Immigration Services - USCIS), já que estava prestes a perder o visto no território estadunidense.

Destarte, avocando um daqueles recursos que pretende consentir o contato com situações de uso "real" da língua, não proporei uma atividade de cunho intrinsecamente didático-metodológico, que apresentará exercícios estruturais que exploram a gramática, a escuta de palavras, vocábulos ou questões de interpretação, como comumente se apresenta, a exemplo de muitas atividades ${ }^{9}$ que até eu mesmo próprio elaborei em minhas práticas de ensino de LI, baseado nos modelos que vários manuais e livros de apoio trazem, quando da ministração de aulas de inglês báșico em úma escola de idiomas e enfrentei as freimas do insucesso.

Mas viso a uma díscussão de cunho mais teórico, com o escopo de nos precatarmos que possivelmente os malogros que enfrentamos em uma sala de aula de língua estrangeira, antes de ser uma questão eminentemente metodológica e de escolhas didáticas, é uma questão que perpassa a (des)constituição subjetiva dos alunos frente à língua aprendida e ensinada. Uma questão marcada por conflitos e embates, e que merece algumas considerações.

Para tanto, inscrito nos espaços analíticos da Linguística Aplicada, embasado nos pressupostos da teoria discursiva pecheutiana, nos estudos bakhtinianos acerca de língua e sujeito, e nas problematizações pós-culturalistas de identidade (HALL, 2006; BAUMAN,

\footnotetext{
${ }^{9}$ Algumas destas atividades, de minha própria autoria, estão disponíveis no sítio www.eslprintables.com. Destaco duas delas, em que é possível ser observadas essas questões de estruturalidade e gramaticalidade sistêmicas da língua, as quais podem ser acessadas nas seguintes referências:

FERREIRA-ROSA, I. Movie Activity - She's the man. Eslprintables, 15/07/2009. Disponível em http://www.eslprintables.com/cinema_and_television/movies/comedy_movies/she_s_the_man/Movie_Activity_ She_s_the_man_259770/\#thetop

Movie Activity - Bulletproof Monk. Eslprintables, 20/10/2008. Disponível em

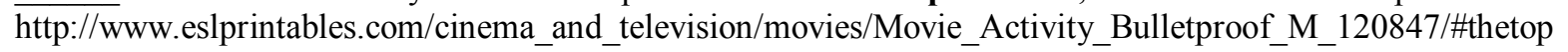


2005), empreenderei ao meu propósito, observando o tripé língua, sujeito e identidade, enquanto um espaço confluente no processo de ensino e aprendizagem de uma LE, em cujo ínterim se estabelecem relações de (des)identificações, produzindo subjetividades.

Em um primeiro momento, a partir da discursividade instaurada por enunciados produzidos, sobretudo, nas locuções estabelecidas entre Barney e Robin quando do ensinar e tornar-se americano, problematizarei a língua que se apresenta/ensina/aprende face à LM que já constitui os sujeitos-aprendentes de uma LE.

Posteriormente, seguindo os mesmos nortes emblemáticos desse discurso fílmico, centrarei na discussão sobre a construção de sujeitos no âmbito educacional do processo de ensino-aprendizagem de uma LE.

E, por fim, deter-me-ei no como "se tornar sujeito" frente à língua estrangeira, mediante práticas identitárias que constroem subjetividades; e a maneira pela qual se podem levar em consideração essas produções subjetivo-identitárias, pensando em tomadas de posição de forma a se minimizar, ou até mesmo extirpar, as freimas do insucesso que atravancam nossas práticas de ensino de uma língua estrangeira.

\section{A língua que se ensina-aprende: idioma estável versus espaço movediço de identificações}

Recorrentemente, verifica-se, em aulas de línguas estrangeiras, e doravante me referirei sempre ao ensino de língua inglesa, o que Barney, ensinando o que é ser de fato um americano, tenta fazer a Robin, quando ele tenta ajudá-la a memorizar respostas a questões que possivelmente seriam perguntadas no teste de cidadania - por exemplo: quantas estrelas a bandeira estadunidense possui? Como são chamadas as dez primeiras emendas da constituição dos Estados Unidos? ${ }^{10}$ Barney assim o diz: "Pronta para o teste talvez, mas pronta para ser uma americana? Não nessa vida! Para você ser uma americana, temos que tirar de você a canadense que ai está" ${ }^{11}$ (HIMYM*, 2009, grifos meus).

\footnotetext{
${ }^{10} \mathrm{O}$ diálogo se passa nos seguintes termos entre Barney e Robin:

Barney: How many stars are on the flag?

Robin: 50 , one for each state.

Barney: What are the first ten amendments to the Constitution called?

Robin: The Bill of Rights. Look, Barney, I know all this! I'm ready! (HIMYM*, 2009)

${ }^{11}$ Minha tradução para "Ready for the test maybe, but ready to be an American? Not on your sweet life! For you to be an American, we got to get the Canadian out of you".

* Usarei sempre esta abreviatura para referir à seguinte referência: HOW I met your mother. Criação de Carter Bays e Craig Thomas. Produção de 20th Century Fox Television. $5^{\text {a }}$ temp., $5^{\circ}$ episod. Nova York: CBS, 19 de outubro de 2009. Rede de comunicação aberta. Transmissão gravada em 1 DVD (21 min), son., color.
} 
É o que analogicamente, nos contextos do ensino de inglês tanto em escolas de idiomas quanto em escolas regulares, tentamos fazer aos nossos alunos: que esqueçam o brasileiro que os constitui, mediante o ato de tirar-lhes dos limites familiares da língua materna, e os transpor aos limites do desconhecido, do estrangeiro. Aos domínios de um idioma homogêneo, transparente e que, às vezes, pode não lhes dizer absolutamente nada, fato que voltarei mais adiante de forma pormenorizada.

Queremos que eles esqueçam a língua portuguesa para dar espaço à língua inglesa, haja vista não ser raras as vezes em que ouvimos enunciados como: "Vocês têm que deixar o português do lado de fora quando entrarem para as aulas de inglês", "Esqueçam português! Agora é aula de inglês", "Se ficarem presos ao português, nunca aprenderão inglês!". E quando evocamos a língua portuguesa nas aulas é somente com vistas à tradução ou comparações que ensejem a compreensão de um fator da ordem da gramática, vocabular e/ou aspecto cultural divergente ou até mesmo convergente com a LM.

Parece, conforme aponta Coracini (2003, p. 143), “que, a partir de Saussure, a relação entre as línguas permaneceu uma relação de código, externa ao próprio sujeito, visto como falante, mero usuário a quem caberia escolher adequadamente as formas para melhor se comunicar". Língua, no contexto de aula de uma LE, é, portanto, comumente concebida como um código homogêneo e estável, cujas estruturas, em uma relação unilateral e unívoca, são apresentadas aos alunos. Digo de tal modo por que, como é que se inicia, usualmente, a ensinar inglês às crianças e talvez até mesmo aos adultos?

Resposta que vislumbramos nos atos pedagógicos de Barney quando diz que talvez Robin esteja preparada para o teste de cidadania, mas não para ser uma verdadeira americana e por isso ele preparou algumas questões:

Barney: É por isso que elaborei estas perguntas! Questão um: quem é esta pessoa? (mostrando a foto da Rainha Elizabeth II)

Robin: Rainha Elizabeth II

Barney: Não. A resposta é Elton John. Questão dois: Que diabos é isso? (mostrando a foto de uma partida de xadrez no gelo)

Robin: Oh, xadrez no gelo! Um esporte praticado...

Barney: Errado, a resposta esperada seria "Não me interessa! É idiota! Vamos comprar algo ruim para nós, e processar as pessoas que o fabricaram". Isso é 
América, Robin! ${ }^{12}$ (HIMYM, 2009)

Tal ato de Barney representa ações concretas que empreendemos em nossas salas de aula de língua estrangeira. Ou seja, é por meio de flashcards, imagens, gestos, desenhos, pictionaries, que palavras vão sendo apresentadas e afixadas a objetos: saudações (greetings), cores (colors), animais (animals), frutas (fruit), vestuário (clothes) e assim por diante, que vão se entremeando às formas sintático-gramaticais do verbo ser/estar (verb to be), do presente (Simple Present), do presente contínuo (Present Continuous), do passado (Simple Past), em uma sucessão quase canônica e imutável nos manuais didáticos de ensino de LI.

E de forma unilateral e unívoca, porque as palavras são apresentadas com, no máximo, dois sentidos, como se não houvesse variações sêmicas, a exemplo da palavra mandioca ao longo do território brasileiro. Ensina-se que blue é sempre azul: Minha camiseta é azul (My Tshirt is blue), As nuvens são azuis (Clouds are blue), Minha cor preferida é o azul (My favorite color is blue). Alunos assim o assimilam. Quando, abruptamente, encontram uma construção do tipo, I am blue, mecanicamente, entendem Sou/Estou azul. Qual a significação que esse enunciado trará aos sujeitos-aprendentes? Definitivamente, uma construção abstrusa.

Ou então, para citar mais uma situação emblemática da unilateralidade e univocidade no contexto de ensino-aprendizagem de inglês, aludo àquelas célebres perguntas para quais ensinamos respostas unímodas, mediante diálogos - as famosas conversations: qual é o seu nome? (What is your name?), como você está (How are you?), que respectivamente devem ser respondidas: Meu nome é... (My name is...), Estou bem, obrigado (I am fine, thanks/Fine, thank you!).

Mas, por que apresentar/ensinar respostas unímodas? Alunos deverão, por exemplo, sempre estar bem? E se for um dia em que algum deles não estiver em situação de dizer um "estou bem, obrigado", mas um "estou puto da vida"?

E o que dizer então das listas de palavras (vocabulary) trazidas ao lado dos textos para facilitar a leitura?

\footnotetext{
${ }^{12}$ Minha tradução para:

Barney: That's why I've created these questions! Question 1: Who is this? (Showing Queen Elizabeth II's picture) Robin: Queen Elizabeth II

Barney: No. The answer is Elton John. Question 2: What the hell is this?! (Showing a curling match)

Robin: Oh curling! Umm it's a sport played by...

Barney: Wrong! The answer we were looking for was "I don't care! It's dumb! Let's go buy something that's bad for us and sue the people who made it!" That's America, Robin!
} 
Daí eu defender que, quando do apresentar e ensinar a língua inglesa em um contexto educacional, professores colocam os alunos frente a um idioma único, homogêneo, invariável, encaixando-os a lugares preestabelecidos, inscrevendo-os em posições previamente delimitadas, engessando a constituição desses sujeitos-aprendentes face aos meandros discursivos da LE com que estão tomando contato, a exemplo do fine trazido em sua grande maioria nos primeiros diálogos ouvidos/memorizados, configurando um lugar estremado no qual todos devem estar partilhando de um único estado emotivo, que muitas vezes pode não dizer nada a um aluno deprimido ou cujo sentimento não condiz com o apresentado pelo livro/professor.

Ora, uma vez já falantes de um língua, no caso a portuguesa, porque sempre nos referimos ao contexto brasileiro, os alunos já são sujeitos em uma língua em cujo ínterim se sentem completos, totalizados e realizados. A língua materna ${ }^{13}$, conforme já asseverou Coracini (2003), no nível consciente, permite ao sujeito a ilusão de unicidade, centralidade e origem do dizer, vendo-se capaz de se autocontrolar e controlar o seu interlocutor, já que se vê capaz de controlar os efeitos de sentidos de sua enunciação.

$\mathrm{Na}$ verdade, sujeitos-aprendentes da língua inglesa são "um já-sujeito" em língua portuguesa em cuja discursividade, (des)construíram-se e (des)constituíram-se enquanto locutores que se viram falados e falaram por ela. Uma língua que já lhes permitiu os regalos dos esquecimentos número 1 e número $2^{14}$. Um lugar seguro e plácido em cujos domínios sentem-se realizados, porque se expressam e são expressos por ela; e, por meio dela, tornam-se verdadeiros sujeitos que falam, ouvem, constroem axiologias das situações, mediante interações que já estabeleceram e ainda estabelecem com o outro (seu interlocutor, o mundo e seus objetos, si mesmo). Já se viram refletidos nos signos que compõem sua LM, mas não apenas seus reflexos foram vivenciados, como também já se refrataram nesses domínios semióticolinguísticos, usando as palavras de Bakhtin/Volochinov (2006).

Ainda na esteira conceptual desse filósofo russo da linguagem, destaco o fato do ser humano nascer em um meio semiótico. Desde seus tenros anos de existência, o homem,

\footnotetext{
${ }^{13}$ Salvo casos de bilinguismo.

${ }^{14}$ Segundo Pêcheux (1997), o esquecimento número 1 remete à ilusão do sujeito falante que se vê como a fonte, a origem do seu discurso; e o número 2 àquela que faz o sujeito se perceber enquanto o mestre e dominador do seu dizer; ilusões essas que são estruturantes, haja vista serem incisivas para a existência de sentidos e sujeitos e necessárias para que a linguagem funcione nas produções sentidurais e nos sujeitos. São elas que dissimulam o fato do sujeito ser cindido, clivado, heterogêneo, interpelado pelas condições de produção, dinâmico e interativo, constituído na interpelação social e na relação com o outro, cujos enunciados são atravessados por discursos outros e em sua voz, vozes outras ressoam, e por isso tais ilusões serem apodíticas no funcionamento da linguagem.
} 
conforme aponta Bohn (2005, p. 17), corroborando Bakhtin/Volochinov (2006), está rodeado "por gestos, sons, movimentos corporais. Nasce, vive dentro das palavras que convidam, comentam, produzem sentidos, às vezes repreendem, interditam”.

São desde os seus primeiros dias de vida que os alunos entram em contato com esse universo implexo e mirífico, mergulhando neste oceano de signos, cujas "ondas crescentes de ecos e ressonâncias verbais, como as ondulações concêntricas à superfície das águas" (BAKHTIN/VOLOCHINOV, 2006, p. 36), permitem-lhes construir sua consciência que, paulatinamente, vai se delineando mediante a ação desses signos, constituindo o interior desses alunos, "formatando sua identidade, desenvolvendo as representações de sua consciência, criando um sentimento de pertencimento" (BOHN, 2005, p. 17).

De fato,

a própria consciência só pode surgir e se afirmar como realidade mediante a encarnação material em signos. Afinal, compreender um signo consiste em aproximar o signo apreendido de outros signos já conhecidos; em outros termos, a compreensão é uma resposta a um signo por meio de signos. E essa cadeia de criatividade e de compreensão ideológicas, deslocando-se de signo em signo para um novo signo, é única e contínua: de um elo de natureza semiótica (e, portanto, também de natureza material) passamos sem interrupção para um outro elo de natureza estritamente idêntica. Em nenhum ponto a cadeia se quebra, em nenhum ponto ela penetra a existência interior, de natureza não material e não corporificada em signos. [...] A consciência individual é um fato sócio-ideológico. (BAKHTIN/VOLOCHINOV, 2006, p. 32-33)

Uma vez já construída sua consciência que "adquire forma e existência nos signos criados por um grupo organizado no curso de suas relações sociais", sendo que esses signos "são o alimento da consciência individual, a matéria de seu desenvolvimento, e ela reflete sua lógica e suas leis" e "a lógica da consciência é a lógica da comunicação ideológica, da interação semiótica de um grupo social" (BAKHTIN/VOLOCHINOV, 2006, p. 34), os sujeitosaprendentes não podem apagar tal consciência porque esta já faz parte de sua própria constituição.

Quando já tornados sujeitos que se serviram da palavra para se expressarem ao outro, que se definiram em relação ao outro e à coletividade; já trilharam as amarras intricadas da interação semiótico-ideológica com outrem, pois "a palavra é uma espécie de ponte lançada entre mim e os outros" (BAKHTIN/VOLOCHINOV, 2006, p. 115), não há como obliterar essa construção da consciência e suas representações, a formatação de identidades e os sentimentos 
de pertença, de completude, de totalidade dos sujeitos-aprendentes vivenciados em sua primeira língua.

Por isso, torna-se tão forâneo, distante, e não raras vezes incompreensível, apresentar aos sujeitos-aprendentes de inglês palavras e estruturas unilaterais e unívocas, um idioma homogêneo, estável, imutável quando já tiveram contato com a movência das ondas crescentes de ecos, vozes, dizeres e ressonâncias verbais do oceano de signos que lhes permitiu construir sua consciência. Eles não poderão se ver refletidos nem refratados em tal idioma, pois, por exemplo, como é que se verão em uma língua que lhes permite somente perguntar pelo estado que seus interlocutores estão passando, usando, no máximo, duas formas: How are you? How do you do?, ao passo que, em sua LM, são inúmeras as formas de dizer: como você está? Tudo bem? Como passou nestes últimos dias? Tudo em cima? E aí, belê? e assim por diante ...? Definitivamente, não se verão.

No entanto, pode-se dizer que mais estruturas serão ensinadas posteriormente, com o avançar dos níveis. É bem verdade, mas em uma ordem cronológico-pedagógica tão rígida que não é tão raro alunos quererem saber mais e ouvirem réplicas do tipo: "Não vem ao caso agora. Você aprenderá mais a frente ou no próximo nível". E o que dizer de alunos que estudam há tanto tempo inglês e quando vão assistir a um filme sem legendas ou então estabelecer uma interação com falantes e/ou nativos de uma LE, não conseguem entender quase nada? Ouvem, por exemplo, um What's up? ou What's popping? (variações do conhecido How are you?) e não sabem do que se trata?

Com certeza, a frustração, decorrente dessa inércia sentida em contraste ao já conhecido balouço das ondas do oceano de signos constituinte de sua primeira língua ${ }^{15}$, imperará e procederá à desistência, à renegação, que nos é tão trivial, principalmente nos anos iniciais de contato com a LI.

Portanto,

esse estar-já-aí da primeira língua é um dado ineludível, mas essa língua é tão onipresente na vida do sujeito, que se tem o sentimento de jamais tê-la aprendido, e o encontro com uma outra língua aparece efetivamente como uma experiência totalmente nova. A novidade, entretanto, não está no encontro

\footnotetext{
${ }^{15}$ Não me proponho à distinção entre língua materna e primeira língua que serão tomadas ao longo deste trabalho como sinônimos. Tanto uma expressão quanto outra aludirão a processos identificatórios que o sujeito estabelece com a linguagem, consequentemente língua materna ou primeira língua, pelos crivos de uma constituição sujeitudinal e uma construção identitária; aquela em cujo ínterim movente sígnico-ideológico o sujeito construiu sua consciência e portanto sua(s) identidade(s).
} 
com o fenômeno lingüístico como tal, mas nas modalidades desse encontro. (REVUZ, 1998, p. 215, grifos meus)

Antes de me preocupar tão desatinadamente com questões didático-metodológicas, devo atentar-me ao "como" apresento a LE aos meus alunos. Como os coloco frente à língua e como essa língua é colocada frente a eles. É preciso me precatar quanto ao modo como promovo o encontro dos meus alunos com a LE ensinada.

Será um encontro linguofágico? Em que a segunda língua deve absorver a primeira, em uma relação de supremacia absoluta, de relevância fundamental e de insígnia inquestionável? Uma língua hegemônica e homogênea - estranha, do outro, do estrangeiro - que deve avançar aos limites familiares da LM preeminentemente, usurpando o lugar do brasileiro que ali está, anuviando os já-ditos, as vozes, o saber discursivo que habitam a primeira língua?

Sob os influxos da globalização, que instaura um socioculturalismo ideológico mundial, parecem ser essas as modalidades de encontro com uma LE mais recorrentes: o linguofagismo e a desterritorialização.

E essas modalidades, em sua grande maioria, provocam desidentificações, pois o receio do estranho - fechado, monovalente, preestabelecido, tolhedor - frente ao conhecido, ao familiar da LM, desestabiliza e instaura, mormente, uma contraidentificação, uma repulsa à LE.

Por isso, a preocupação ser concernente às modalidades do encontro com a segunda língua, pois é imprescindível que se criem espaços para proximidades, para uma inscrição, uma tomada de posição mediante processos identificatórios. De acordo com Serrani-Infante (1998), encontros com segundas línguas fazem parte da ordem de "coisas a saber", mas não um saber que se ensina, antes, um saber que existe produzindo efeitos. "De fato, no encontro com mais de uma língua nacional, o eu, de fato, terá encontros com rede de memórias discursivas nas quais se inscreverá por filiações identificadoras” (SERRANI-INFANTE, 1998, p. 253).

Por conseguinte, o que se deve pensar é em promover aberturas necessárias para que os alunos possam estabelecer processos identificatórios com a língua inglesa que estão aprendendo, por meio de uma simples abdicação da transparente homogeneidade e superioridade da LE. É necessário aos sujeitos-aprendentes transparecer o espaço movediço da língua e nele e por ele estabelecer identificações. 


\section{Sujeito que inscreve-inescreve nos domínios da língua estrangeira: (contra)identificações}

A língua estrangeira não deve ser o lugar altissonante cujos domínios sobrepujam a quaisquer outros pela sua rigidez, consistência e aparente homogeneidade. Não pode ser o espaço no qual deixo tudo que me constituiu na primeira língua e me transformo em um sujeito outro. Antes, deve ser um lugar outro no qual me inscrevo mediante filiações identificadoras; e “inscrever-se numa segunda língua é re-significar e re-significar-se nas condições de produção de outra língua, o que significa, em última instância, 'saber' essa língua, isto é ser falado por ela" (CORACINI, 2003, p. 153).

Dessa forma, torna-se indeclinável aos sujeitos-aprendentes verem-se nessa língua. Serem falados e falarem por ela. Enfim, estabelecerem uma relação de identificação com esse outro, estranho, que não usurpa o terreno familiar da primeira língua, mas a partir dele e em seus domínios lhes permite construir um lugar para que esse estrangeiro habite, provocando o que Serrani-Infante (1997) chamou de desarranjo subjetivo, todavia um desarranjo deslocativomovente que possibilita um rearranjo significante. Um rearranjo que provocará o aparecimento de outras vozes, outros confrontos, outros conflitos, outras identidades, ponto que voltarei mais adiante de forma mais circunstanciada.

Se o for ao contrário, não havendo identificações, o sujeito se inescrevendo na LE, haverá talvez imitações que não revelarão uma subsistente constituição sujeitudinal dos alunos frente à língua ensinada. Estes não passarão de meros reprodutores que memorizaram diálogos e encenações enunciativas (os fámosos role playing, drills). Quiçá consigam decodificar, mas não serão capazes de "estabelecer uma interlocução com outro sujeito, construindo sentidos, enunciando e compreendendo, ou seja, significando enunciados realizados por outros sujeitos nessa língua segunda ou estrangeira" (GUILHERME DE CASTRO, 2008, p. 06). Isto é, não desenvolverão a competência oral-enunciativa, termo cunhado pela referida autora, para aludir àquela capacidade de enunciar oral e significativamente, instaurada em "um processo estreitamente ligado a inscrições identificatórias na discursividade da língua-outra e tal processo decorre das identificações e das desidentificações vivenciadas pelo sujeito em relação à LE e também em relação à sua língua materna" (GUILHERME DE CASTRO, 2008, p. 06).

E, havendo somente imitações, o processo de ensino-aprendizagem de inglês não passará de aparências, superficialidades e falsas impressões, a exemplo do que, voltando à 
discursividade do seriado "Como conheci sua mãe" que suporta emblematicamente minha discussão, Barney tentou impingir em Robin.

Ao se propor a transformá-la em uma verdadeira americana, ele, mediante repetições e encenações via flashcards, permitiu-lhe alguns mecanismos (gestos, atitudes, uso de signos ideológicos) que a fizessem se sentir, de fato, uma legítima estadunidense, conforme se observa no excerto abaixo:

Narrador: E no final daquela noite, Barney havia transformado Robin em uma verdadeira americana.

(Barney mostrando uma foto)

Robin: Imagino que seja... Jefferson?

Barney: Isso! O vizinho de Archie Bunker foi o George Jefferson.

Robin: Irrull! Estou arrebentando! Agora estou detonando a América!

Barney: Certo, certo, baixa a bola aí! Para provar que você é tão americana quanto torta de maçã e a obesidade infantil que provoca... quem é esse?

Robin: Este, Barney, é o ator americano idolatrado por milhões de pessoas, o cara do "Oi, Vern", daqueles seriados mais populares da Ernest filmes. E o nome dele é Jeff Foxworthy.

Barney: Jeff Foxworthy? Não. É Jim Varney. Você está brincando? Não sabia disso?

Robin: Eh, é o Jeff Foxworthy, imbecil e ponto final! Agora cale a boca!

Barney: Não está apenas errada, como você está usando todas suas armas e me insultando no processo. Robin Sherbatsky, você é uma americana ${ }^{16}$ ! (HIMYM, 2009)

Contudo, ao outorgar a Robin, por meio de um gesto de continência, o designativo de americana, Barney, na ânsia de delir do interior da amiga a canadense que ali já estava constituída, não the possibilitou nada mais que uma fantasia, uma máscara estadunidense que a

\footnotetext{
${ }^{16}$ Minha tradução para:

Narrator: And by the end of the night Barney had turned Robin into a real American.

(Barney showing a picture)

Robin: I want to say... Jefferson?

Barney: Correct! Archie Bunker's neighbor was George Jefferson!

Robin: Boo-yah! I am nailing this! God, I am buzzing on America right now!

Barney: All right, all right, hold your horses! Now to prove that you are as American as apple pie and the childhood obesity it leads to.....who is this?

Robin: That, Barney, is the American actor, beloved by millions, the "Hey, Vern" guy from the popular series of Ernst films. And his name, Jeff Foxworthy.

Barney: Jeff Foxworthy? No. It's Jim Varney. You're kidding me? You don't know that?

Robin: Uh, that's Jeff Foxworthy dumbass, end of story! Now shut your stupid face!

Barney: Not only are you wrong, but you are belligerently sticking to your guns and insulting me in the process. Robin Sherbatsky, you are an American!
} 
fez, com muitas superficialidades e aparências, sair pelas ruas nova iorquinas imitando, quase beirando ao grotesco "macaqueal"17, o "ser um verdadeiro americano".

As cenas a que assistimos são cômicas. Robin passeia pelas ruas jogando as pernas, remexendo os braços, sacolejando o corpo, atirando latinha nas alamedas por onde passavam os carros e pensando: "Isso mesmo, vou ser uma americana, pessoal! Talvez eu roube uma loja de bebidas, talvez não. A decisão é minha! APRENDA INGLÊS! (gritando para um táxi que passava) ${ }^{18 "}$ (HIMYM, 2009).

O que se presencia é um simulacro que tenta abafar, encobrir, enfim, obliterar a constitutividade que era imanente ao sujeito-canadense Robin. E, por ser um simulacro, não era um lugar seguro, consistente e perenal, construído por meio de relações identificatórias. Foi um outro, um estranho distante de seu familiar, que não the permitiu estabelecer filiações identitárias e, por isso, quando se vê frente do Hoser Hut

Robin (pensando): Hoser Hut [um bar canadense de Nova Iorque]! Posso entrar e beber um pouco. Não! Essa vida ficou para trás. Esqueça! Bem, eu poderia entrar e tomar somente uma cerveja. Que mal há nisso? É um país livre. (Entra no bar)

Robin e todos (cantando o hino nacional do Canadá): Oh Canadá! Nosso lar e terra nativa... Robin (chorando e dizendo): Oh, meu Deus, como eu senti saudades disso!

Robin (chorando e cantando) e todos (cantando): Verdadeiro amor dos patriotas... ${ }^{19}$. (HIMYM, 2009)

, não resiste, não conségue deixar sua constitutividade para trás e logo deixa de lado o tal estranho, o tal outro que lhe foi apresentado, para voltar aos domínios seguros de suas raízes que lhe deixaram saudades.

Aparentemente, havia se tornando uma americana, mas, na realidade, havia estabelecido uma contraidentificação com o "outro estadunidense" tão tenaz e sentindo tanto a falta do familiar e conhecido acabou voltando de fato para o Canadá:

\footnotetext{
${ }^{17}$ Qualificador derivado de macaquear para aludir ao atributo resultante do processo de arremedar, aos moldes dos macacos; de imitar servilmente, passivamente ou de maneira ridícula. Com efeito, o que presenciamos nas aulas de LE, não raras vezes, são práticas de imitações-repetições servis e passivas que levam os alunos a empreenderem verdadeiras macaquices linguageiras para se tornarem de fato falantes de uma língua estrangeira.

${ }^{18}$ Minha tradução para: “Oh yeah, I'm gonna be an American, y’all! Maybe I'll rob a liquor store, maybe I won't! My choice! LEARN ENGLISH! (yelling at a taxi that was passing). (HIMYM, 2009)

${ }_{19}$ Minha tradução para:

Robin (thinking): The Hoser Hut! I could duck in for a drink. No, no, that life's behind me. Forget it! Well, I could in for just one beer. What's the harm in that? It's a free country! (Gets in the bar)

Robin and everybody (chanting Canada's national anthem): Oh Canada! Our home and native land...

Robin (crying and saying): Oh, God, I miss it!

Robin (crying and chanting) and everybody (chanting): True patriots love...
} 
Narrador: Quando Barney finalmente encontrou sua tia Robin, não foi uma visão agradável!

Barney: Bom dia!

Robin (gemendo): Barney? Oh meu Deus, o que aconteceu ontem?

Barney: Você deu uma de canadense.

Robin: De que forma?

Barney: DESSE TANTO (abrindo as janelas). Oh, era para ser uma vista dramática do céu de Toronto. Você está em Toronto!!

Robin: Meu Deus! Certo. Estou começando a lembrar. Entrei no Hoser Hut... e encontrei um time feminino de xadrez no gelo... começamos a beber. E o que lembro depois é que elas me convidaram para um show duplo do Bryam Adams e Rich Little em Toronto. Mas como você me encontrou?

Barney: Você me ligou e disse que nunca mais iria voltar. Então, eu peguei um avião, voei sobre o Atlântico...

Robin: Canadá não é do outro lado do Atlântico.

Barney: Você está falando bobagens. Agora, escuta, você pisou na bola. Está bem.

Mas o teste vai ser daqui algumas horas...

Robin: Barney, não vou fazer o teste.

Barney: Meu Deus, você ainda está bêbada.

Robin: Olha, eu agradeço a sua ajuda, mas... quem estou tentando enganar? Sou canadense! Sempre serei!

Barney: Isto é rídículo! Vamos colocar um pouco de café em você, te deixar sóbria, e te levar de volta a Nova Iorque para aquele teste. Mas antes de tudo isso, vamos dar uma rapidinha nesta cama, porque quarto hotel... (ela vira-se com cara de poucos amigos). Certo, vamos tomar um pouco de café ${ }^{20}$. (HIMYM, 2009)

${ }^{20}$ Minha tradução para:

Narrator: When Barney finally tracked down your Aunt Robin, it wasn't a pretty sight. Barney: Good morning!

Robin (moaning): Barney? My God, what happened last night?

Barney: You...went Canadian.

Robin: How Canadian?

Barney: THIS CANADIAN! (opens the windows) Oh. That was supposed to be a dramatic view of the Toronto skyline...you're in Toronto!!

Robin: Oh my God. It's coming back to me. I, uh, I went into the Hoser Hut and I met this women's Curling team. We started drinking and the next thing I know they're inviting me to a Bryan Adams/Rich Little double bill in Toronto. How did you find me anyway?

Barney: You called me! Said you were never coming back. So I jumped on a plane, flew across the Atlantic...

Robin: Canada isn't across the Atlantic.

Barney: You're talking nonsense. Now listen, you slipped up, it's fine. The test is in a few hours...

Robin: Barney, I'm not taking the test.

Barney: God, you're still drunk!

Robin: Look, I appreciate your help, but who am I kidding? I'm Canadian! I always will be.

Barney: Now that's ridiculous! We're gonna get some coffee in you, we'll sober you up, and get you back to New York for that test! But, before any of that, we're gonna do it, on this bed because...hotel room! ... (She turns back and has an evil look) Ok, let's get some coffee. 
Entretanto, ao chegar aos domínios familiares de seu conhecido território, alcança uma surpresa que esfacela sua constitutividade:

\section{(No aeroporto em Toronto)}

Robin (para a mulher atendente da lanchonete): Me dê dois cafés.

Atendente: $\$ 3.50$, por favor. Ei, o que achou do jogo de ontem à noite?

Robin: Que jogo?

Atendente: Os Leafs ganharam dos Edmonton. Beauchemin marcou por entre as pernas do goleiro na prorrogação.

Robin: Ah, acho que perdi então.

Atendente: Ah, desculpa. Você é americana. Aqui está seu troco.

Robin: Não sou americana!

Atendente (colocando a mão na cintura): Dinheiro americano? Não assistiu ao jogo dos Leafs? Não disse "por favor" nem "obrigada" pelo café? Você certamente não parece uma canadense!

(Robin pega os cafés e sai encabulada)

Barney: Qual o problema? Além do fato de que esta nota de cinco dólares que eles te deram é azul.

Robin: Nossa! Não sou americana e aparentemente, também não sou canadense.

Barney: E tem crianças jogando hóquei no verso da nota! É como se quisessem que tirássemos sarro de vocês. (Pegando uma moeda) Olha esta moeda! Esta tem um alce, esta tem um castor, e todas elas têm o Elton John atrás!

Robin: Quando eu me mudei para os Estados Unidos, jurei a mim mesma que não iria mudar. E aqui estou eu, no lugar mais canadense do universo - Tim Horton's a um quarteirão do Hall da Fama do Hóquei, e não me encaixo aqui. É como se eu não tivesse mais um país! ${ }^{21}$ (HIMYM, 2009)

\footnotetext{
${ }^{21}$ Minha tradução para:
}

(At the airport in Toronto)

Robin (to coffee shop's cashier): Yeah, give me tow coffes.

Cashier: \$ 3.50, please. Hey, what did you think of the game last night?

Robin: What game?

Cashier: The Leafs beat Edmonton. Beauchemin went five-hole in OT [abbreviation of overtime].

Robin: Oh, I guess I missed it.

Cashier: Oh, sorry. You're American. Here's your change.

Robin: I'm not American.

Cashier: American money? Didn't watch the Leafs game? No "please" or "thank you" for the coffee? You sure don't seem like a Canadian.

Barney: What's wrong? Other than the fact that this five dollar bill they gave you is blue!

Robin: Wow. I'm not American and apparently I'm not Canadian either!

Barney: And there's kids playing hockey on the back! It's like you want us to make fun of you! Hey! Look at this money! This one has a moose! This one has a beaver! And they all have Elton John on the back! Robin: When I moved to the States, I swore to myself I wasn't going to change. And yet, here I am in the most Canadian place in the universe, Tim Horton's, around the corner from the hockey hall of fame! And I don't belong. It's like I don't have a country. 
Robin não se vê nem americana e nem canadense e, portanto, parece ser um sujeito sem um país, uma origem, sem marcas de pertencimento, enfim, sem uma imanente constitutividade sujeitudinal.

Não é essa (des)constituição que repetidas vezes presenciamos em nosso contexto de ensino-aprendizagem de línguas estrangeiras? Fazendo uma correlação canadense $\Leftrightarrow$ LM e americano $\Leftrightarrow$ LE na discursividade instaurada em "Como eu conheci sua mãe", já não assistimos a esse episódio emblematicamente em nossas práticas didático-pedagógicas?

Muito provavelmente encontraremos numerosas respostas afirmativas para estas perguntas, por que não é insólito deparar com professores que querem transformar seus alunos em verdadeiros americanos. Treinam arduamente, pronúncia e prosódia. Gastam semanas e mais semanas, ensinando aos sujeitos-aprendentes a perfeição de articular o som do th: /ð/ e / $\theta /$. Anseiam por extirpar qualquer sotaque que revele não ser um falante nativo, afinal, o grande objetivo é ser/parecer de fato um native speaker.

Desse modo, avulta-se o estranho, o outro deve dominar os terrenos familiares de minha constituição enquanto um sujeito já falante de uma primeira língua. Deve-se esquecer o que sou - brasileiro cuja LM é o português - para incorporar o estrangeiro. Tenho que ser tal qual, falar como tal, agir, pensar, articular os sons, e de forma muito ádvena e inconcebível a um sujeito que já construiu sua consciência no agitar do oceano de signos de sua primeira língua: fechada, sistêmica, monovalente e unívoca.Palavras são desprovidas de riquezas sêmicas e há um só modo de pronunciá-las.

Por meio de imitações e repetições, devo adquirir falsas aparências e superficialidades de um outro-estranho, com o qual muitas vezes não me identifico e não me vejo nas "macaquices" que me levam a empreender, pois, por exemplo, por que devo gostar de toranja (grapefruit), aos moldes dos drills que ainda se ensinam por aí e que tem nos diálogos e exercícios orais: I like grapefruit a lot, My favorite fruit is grapefruit, se é uma fruta que nem no Brasil existe (e são raras as pessoas que conhecem/experimentaram)? Por que quando se está aprendendo as frutas em inglês, e se faz a pergunta What's your favorite fruit, não se pode responder I like jaboticaba?

É por estas e mais outras razões que existem tantas contraidentificações e inescrições no âmbito educacional do ensinar-aprender uma língua estrangeira. Avento o termo inescrição, enquanto extensão teórica advinda de um imbricamento epistêmico-conceptual das noções pecheutianas de tomada de posição, desidentificação e inscrição discursiva, para remeter ao 
ato de um sujeito não se inscrever nos domínios subjetivos da língua estrangeira que está sendo ensinada. Mediante as modalidades de contato com essa LE, na maioria das vezes apresentada como um código fechado, uno e homogêneo, impinge-se nos aprendentes a falsa imutabilidade e aparente transparência da LE. Com efeito, uma língua enquanto um outro, estranho unilateral e unívoco - que deve usurpar os domínios familiares da primeira língua em cuja discursividade esses aprendentes já se constituíram sujeitos. Portanto, uma LE que não réflete nem refrata esses sujeitos, falando deles ou permitindo a eles serem falados por ela; o que os leva à plena inescrição nessa e por essa LE.

$\mathrm{Na}$ verdade, não se abre espaço para filiações, para identificações e, devido a isso, podem-se levar os alunos a ocuparem um não lugar, uma inespacialidade imaginária que os faz não poderem ser vistos nem em sua língua materna, nem se verem na língua estrangeira. Sentirem-se sem um lugar, assim como Robin, sem um país, isto é, sem um espaço identificador, que gera um vínculo de pertencimento.

Por que não se pode ser um brasileiro que fala inglês? Por que não se pode ter sotaque? Por que tenho que falar como o nativo? Por que me tornar um forasteiro em minha própria terra? Por que o estrangeiro deve ocupar os espaços de minha primeira língua? Por que não posso simplesmente construir um espaço em meus domínios subjetivo-linguísticos para o estrangeiro habitar? Não posso simplesmente hospedá-lo?

São questões identitárias que produzem subjetividades. Indagações que conduzem à(a) construção(ões) de identidade(s) por relação de filiações, de pertencimento, de construção de um eu perante a um outro.

\section{Construção de identidades e produção de subjetividades no processo de ensinar/aprender uma língua estrangeira}

O sujeito não é uno, fixo, estável, firmado em um lugar sócio-cultural e ideológico único e hermético, mas marcado por uma contínua alteridade e uma descontínua interpelação ${ }^{22}$. Constrói sua consciência desde os primeiros contatos com o oceano de signos que o rodeia. Sua

\footnotetext{
${ }^{22}$ Interpelação diz respeito ao fato do sujeito ser chamado à existência, representada, segundo Pêcheux (1997, p. 154), por um teatro da consciência, em que a ideologia interpela indivíduos em sujeitos. $\mathrm{O}$ fato do "(eu vejo, eu penso, eu falo, eu te vejo, eu te falo etc.) [vincula-se] de onde se pode captar que se fala do sujeito, que se fala ao sujeito, antes de que o sujeito possa dizer "Eu falo"”, isto é, vincula-se ao lugar sócio-histórico ideologicamente marcado no qual inscreverão os sujeitos.
} 
consciência é um fato socioideológico (BAKHTIN/VOLOCHINOV, 2006) que constrói (des)identificações, identidades, sempre no plural.

O sujeito perenalmente se constitui na e em relação a um outro, marcado pela heterogeneidade, pelas interações que estabelece ao longo da vida. Constitui-se, também, pelos outros com os quais esteve e está sempre em contato: com o mundo e seus objetos, com sujeitos outros, com o meio socioespacial em que está inserido, com ideologias, com sua formação educacional, com textos orais ou escritos lidos/ouvidos, enfim com saberes discursivos anteriores, que falam antes e em outro lugar, aos quais se integrou; ou seja, a memória discursiva que remete às várias vozes e discursos constitutivos da linguagem e do sujeito.

Sendo assim, o sujeito encontra-se em um processo de constante (des)construção mediante às tomadas de posição que está sempre empreendendo. Ao enunciar, o faz de um lugar discursivo marcado por ideologias, vozes e discursos constitutivos, o que não pode levar a se pensar em uma identidade única e estável para os sujeitos-aprendentes de uma LE.

Não estou, portanto, defendendo a identidade nacional brasileira ou a LM, o português, enquanto elementos que devem ser preservados frente à língua inglesa que se ensina nas escolas. Antes, ao longo dessa discussão, estou problematizando as modalidades por meio das quais se colocam os alunos perante a LE e como essa LE é colocada perante aos alunos. Isso porque, na coetaneidade, sujeitos não tếm "uma identidade fixa, essencial ou permanente. A identidade torna-se uma 'celebração móvel': formada e transformada continuamente em relação às formas pelas quais somos representados ou interpelados nos sistemas culturais que nos rodeiam." (HALL, 2006, p. 12-13).

Não se pode projetar uma identidade que prende o sujeito à estrutura, estabilizando "tanto os sujeitos quanto os mundos culturais que eles habitam, tornando ambos reciprocamente mais unificados e predizíveis" (HALL, 2006, p.12). Tais quais os sujeitos, os mundos culturais são marcados pela heterogeneidade, pelas inúmeras vozes

dos outros, caracterizadas, em graus variáveis, pela alteridade ou pela assimilação, caracterizadas, também em graus variáveis, por um emprego consciente e decalcado. As palavras dos outros introduzem sua própria expressividade, seu tom valorativo, que assimilamos, reestruturamos, modificamos. (BAKHTIN, 1997, p. 315) 
"O sujeito, previamente vivido como tendo uma identidade unificada e estável, está se tornando fragmentado; composto não de uma única, mas de várias identidades, algumas vezes contraditórias ou não-resolvidas" (HALL, 2006, p. 12).

Destarte, os sujeitos-aprendentes de uma LE são sempre e necessariamente constituídos pelo outro, por várias identidades. E sendo o estrangeiro inevitavelmente um outro que estaria em contato com eles, como pode haver tantas desidentificações?

Uma resposta a esta pergunta se encontra nas modalidades de ensino. Aquelas que querem obliterar a constitutividade heterogênea, as diferentes vozes que constituem um sujeito já falante de uma primeira língua. Aquelas que querem tornar os alunos meros reprodutores, repetidores, enfim, "macacos” enunciativos da voz do estrangeiro, da voz do material didático e/ou da voz do professor. Aquelas que, mediante a falsa homogeneidade e aparente transparência da LE, querem delir as diferenças, "promovendo uns ao lugar de centro e relegando outros às margens" (CORACINI, 2003, p. 152).

Logo, o que se deve fazer é possibilitar a abertura, a não obliteração das heterogeneidades. É permitir aos alunos identificarem-se com a LE, verem-se no e pelo outro, o estranho. E ““identificar-se com...’ significa dar abrigo a um destino desconhecido que não se pode influenciar, muito menos controlar" (BAUMAN, 2005, p. 36).

Não é querer que o estrangeiro usurpe os domínios discursivos já construídos do sujeito em sua primeira língua. Não é querer que a voz do estranho sobrepuge a outras que constituem a referencialidade polifônica ${ }^{23}$ (SANTOS, 2000) dos sujeitos-aprendentes.

Mas lhes transigir momentos de identificações por meio de ações didático-pedagógicas que não omitam as diferenças, os conflitos. Ações que não apaguem a heterogeneidade e nem as diferenças. Ações que conduzam à construção de identidades, de subjetividades, à condição identificatória de abrigar o outro, mesmo que "aquele que se identifica talvez creia que está capturando o outro, mas é ele quem é capturado" (SERRANI-INFANTE, 1998, p. 253), e, por isso, um outro que não se pode influenciar, muito menos controlar, conforme dito por Bauman (2005).

É necessário que se criem possibilidades, mediante filiações identificadoras, de hospedar esse outro estrangeiro no imaginário sociodiscursivo dos sujeitos-aprendentes, deixá-

\footnotetext{
${ }^{23}$ Segundo Santos (2000, p. 231) a referencialidade polifônica, extensão teórica dos estudos bakhtinianos, indica "a heterogeneidade subjacente às bases discursivas do imaginário sociodiscursivo dos sujeitos. Essa heterogeneidade, por sua vez, é transpassada por discursos distintos. Dessa maneira, as vozes dos sujeitos são entrecortadas por várias outras vozes e por vários outros discursos".
} 
lo habitar em meio às vozes que constituem a referencialidade polifônica desses sujeitos. Finalmente, deixá-los no crivo dos confrontos LM/LE que provocam um desarranjo subjetivo, realizarem um rearranjo subjetivo, instaurador de múltiplas identidades e subjetividades, ássim como o que Robin estabeleceu ao final do episódio.

Quando ela se viu perdida no aeroporto de Toronto, sem nenhum lugar ou constitutividade sujeitudinal, reclamou com Barney esse fato de não ter nenhum país e ele, como um bom amigo, subiu na cadeira e proferiu um discurso depreciativo ${ }^{24}$ que rebaixava os canadenses. E, como consequência, levou uma surra, tendo que voltar para Nova Iorque todo enfaixado e andando de muletas:

Barney: Esses médicos canadenses me enfaixaram, ajeitaram meu queixo, colocaram meu ombro no lugar, e nem me cobraram. Idiotas! (Robin lhe olha torto) Certo, acho que eles não são idiotas. Achei o café extraordinário. Eh, o Canadá não é tão ruim assim. Se fizerem as coisas direito, talvez possam até virar um estado algum dia.

Robin: Barney, eu pensei sobre isso. Quando você se levantou e insultou aquelas pessoas, pensei "É, a América é legal!".

Barney: Hmm •

Robin: E quando aqueles caras colocaram suas tripas para fora, pensei, "É, o Canadá é bem legal também". Na verdade, depois que você desmaiou, pode ser que tenha dado uns socos também... (Ele olha assustado) Então eu decidi. Cidadania dupla! Serei americana e canadense.

Barney: Espera, dá para fazer isso?

Robin: Claro, bobinho. Ao invés de ser uma mulher sem país, vou ser uma mulher com dois.

Barney: Sei.

Robin: Entende?

Barney: Não. (Muito feliz e piscando os olhos) Eu consigo ver com meu olho

\footnotetext{
${ }^{24}$ Que foi da seguinte forma:

Barney: Ok, acabou! (Subindo na cadeira) Atenção Canadá! Eu sou Barney da América, e estou aqui para consertar seu país totalmente errado! (uma música é tocada ao fundo) Número 1: arrumem dinheiro de verdade! Não sei de que jogo de tabuleiro veio isso (mostrando uma nota canadense), mas é uma piada (tentando imitar a maneira como os canadenses pronunciam oj)! Número 2, e esta é muito importante: parem de deixar gatas maneiras como Robin Sherbatsky fugirem, porque, sabem de uma coisa? Não a querem? Vou plantar minha bandeira nela, se é que me entendem, e provavelmente não entendem... e vou levá-la embora deste inferno aqui! Agora podem voltar a ser inúteis (sentando na cadeira).

Minha tradução para:

Barney: Ok, that's it (getting up on the chair). Attention Canada! I am Barney from America, and I'm here to fix your backward-ass country! (a song plays from the back) Number 1, get real money! I don't know what board game this (showing a Canadian bill) came from but it's a "jhoke" (trying to imitate the way Canadians pronounce $j)$ ! Number 2, and this is the biggie, quit letting awesome chicks like Robin Sherbatsky get away! Because guess what? You don't want her? I'm plantin' my flag in her, if you know what I mean, which you probably don't, and getting her the hell out of here! You may now return to being pointless! (sitting on the chair).
} 
esquerdo de novo ${ }^{25}$ (HIMYM, 2009. Grifos meus).

Ser canadense e ser americana foi que o Robin decidiu. Foi esse o rearranjo subjetivo instaurado: avocar a heterogeneidade, assumir múltiplas identidades, trazer o outro às várias vozes que constituíam sua referencialidade polifônica.

\section{Por um (in)acabamento da discussão}

Chego, destarte, aos termos que prenunciam o (não)findar de uma discussão que teve como escopo problematizar a (des)constituição dos sujeitos-aprendentes de uma LE, emblematicamente representada na discursividade de um enunciado filmico-cômico, frente ao movimento língua-sujeito-identidade.

Não tive por alvitre tutelar a língua materna perante a língua estrangeira que se ensina, mas questionei as modalidades de encontro das duas, pois é na forma como eu apresento a LE que talvez residam pontos significáveis que levam às tão triviais contraidentificações que enfrentamos em nossas salas de aula de línguas estrangeiras.

Antes de nós professores ficarmos assaz turbados com questões didático-metodológicas, em uma busca frenética por atividades e sequências didáticas para direcionar nossa prática pedagógica, devemos nos atentar à modalidade pela qual colocamos a língua ante os alunos e os alunos ante alíngua. Como eu, em meu lugar de professor, concebo a língua, vejo-me nessa língua e permito a quem ensino se ver nessa superfície linguística.

\footnotetext{
${ }^{25}$ Minha tradução para:

Barney: Man, those Canadian doctors bandaged me up, reset my jaw, put my shoulder back in its socket, and they didn't even bill me! Idiots! All right, I guess they're not idiots. The coffee was extraordinary. Huh, I guess Canada's not so bad. They play their cards right and maybe they can even become a state someday! Robin: Barney, I've thought about this. When you stood up and told off those people I thought, "Yeah, America's cool!"

Barney: Mmm...

Robin: And then when those guys pounded the stuffing out of you I thought, "Yeah, Canada's pretty cool too!" In fact, after you passed out, I may have taken a few pokes myself. So I've decided, dual citizenship! I'm going to be American and Canadian.

Barney: Wait, you can do that?

Robin: Yea, dummy! Instead of being a woman with no country, I'm going to be a woman with two!

Barney: I see.

Robin: You understand?

Barney: No, I can see out of my left eye again!
} 
Não posso, baseado nos pressupostos sistêmicos herdados do estruturalismo, ver a língua como um código fechado, uno e homogêneo. Não posso impingir em meus alunos a falsa imutabilidade e aparente transparência da LE, como um outro, estranho - unilateral e unívoco - que deve usurpar os domínios familiares da primeira língua em cuja discursividade já se constituíram sujeitos.

É impossível, uma vez que estiveram em contato com a movência das ondas crescentes de ecos, vozes, dizeres e ressonâncias verbais do oceano de signos que lhes permitiu construir sua consciência enquanto fato socioideológico (BAKHTIN/VOLOCHINOV, 2006), que já se viram refletidos e refratados nesses signos, identificarem-se com um código inerte e monovalente.

É abstruso a um sujeito-aprendente de uma LE construir uma relação identificadora com um idioma linguofágico (que absorve/apaga sua primeira língua) e desterritorializante (que não o leva a nenhum lugar, deixando-o sem espaço filiatório).

Permitamos aos alunos uma filiação identificatória ao outro, ao estrangeiro, mediante a abertura de espaços para que eles possam, nos domínios familiares de sua primeira língua, hospedar esse forâneo; para que possam inscrever as vozes da LE em sua referencialidade polifônica.

Não se trata de substituições, mas convivências. Uma autêntica polifonia de discursividades linguísticas, em que não há a supervalorização da LM e nem o enaltecimento supremamente da LE. Antes, um espaço construtor de identidades e subjetividades, constituindo sujeitos capazes de interagir com outrem, atribuindo e construindo efeitos de sentidos.

Sendo assim, este trabalho pode, pois, contribuir para a Linguística Aplicada, mais especificamente na área de ensino-aprendizagem de LEs, na medida em que coloca em questão o apego demasiado e a tenaz apologia a metodologias para o ensino de línguas estrangeiras. Buscando uma reflexão sobre a maneira como se ensina uma LE, a partir do que se entende por língua e sujeito e os modos de encontro que são estabelecidos entre essa LE e os aprendentes dela, mediados pelo professor, ficou evidenciado que mais que preocupações metodológicas e elaboração de manuais didáticos que deem conta do ensino de uma LE em qualquer espaço do mundo, devemos levar em consideração a essência e o imo das questões que perpassam a constituição do sujeito perante a língua, produzindo (des)identificações, pois, do contrário, como já anunciava a epígrafe dessa discussão, nossas ações podem se tornar ingênuas e, quiçá, 
podem contribuir de fato para um processo de ensino-aprendizagem profícuo e instaurador de sujeitos-enunciadores que se viram e falaram pelo outro, pelo estrangeiro que habita em nós, nas palavras de Kristeva (1994).

\section{Referências}

BAKHTIN, M./VOLOCHINOV, V. Marxismo e filosofia da linguagem. Trad. Michel Lahud e Yara Frateschi Vieira. 12 ed. São Paulo: Hucitec, 2006.

Estética da criação verbal. Trad. a partir do francês Maria Ermantina Galvão. 2 ed. São Paulo: Martins Fontes, 1997.

BAUMAN, Z. Identidade: entrevista a Benedetto Vecchi. Trad. Carlos Aberto Medeiros. Rio de Janeiro: Jorge Zahar Ed., 2005.

BRASIL. Secretaria de Educação Básica. Orientações curriculares para o ensino médio: linguagens, códigos e suas tecnologias. v. 1. Brasília: Ministério da Educação, 2006.

BRASIL. Secretaria de Educação Fundamental. Parâmetros curriculares nacionais: terceiro e quarto ciclos do ensino fundamental: língua estrangeira. Brasília: MEC/SEF, 1998.

BOHN, H. Lingüística Aplicada e Contemporaneidade. In: FREIRE, M.; ABRAHÃO, M. H. V.; BARCELOS, A. M. F. (orgs.) Lingüística Aplicada e Contemporaneidade. São Paulo: ALAB; Campinas: Pontes Editores, 2005. p. 11-23.

CANAGARAJAH, S. Reconstructing local knowledge. Journal of Language, Identity and Education. Vol. 1(4), 2002. p. 243-260.

CORACINI, M. J. Língua estrangeira e Língua materna: uma questão de sujeito e identidade. In: _ . (org.). Identidade e discurso: (des)construindo subjetividades. Campinas: Editora da Unicamp; Chapecó: Argos Editora Universitária, 2003. p. 139-159.

FERREIRA-ROSA, I. Movie Activity - She's the man. Eslprintables, 15/07/2009. Disponível em

http://www.eslprintables.com/cinema_and_television/movies/comedy_movies/she_s_the_man /Movie_Activity_She_s_the_man_259770/\#thetop

. Movie Activity - Bulletproof Monk. Eslprintables, 20/10/2008. Disponível em http://www.eslprintables.com/cinema_and_television/movies/Movie_Activity_Bulletproof_M _ 120847/\#thetop

GUILHERME DE CASTRO, M. F. F. Competência oral-enunciativa em língua estrangeira (inglês): fronteiras e limites. 2008. 325 f. Tese (Doutorado em Linguística Aplicada e Estudos da Linguagem) - Programa de Estudos Pós-Graduados em Linguística Aplicada e Estudos da Linguagem, Pontifícia Universidade Católica de São Paulo, São Paulo, 2008. 
HALL, S. A identidade cultural da pós-modernidade. Trad. Tomaz Tadeu da Silva. 11 ed. Rio de Janeiro: DP\&A, 2006.

HOW I met your mother. Criação de Carter Bays e Craig Thomas. Produção de $20^{\text {th }}$ Century Fox Television. $5^{\text {a }}$ temp., $5^{\text {o }}$ episod. Nova York: CBS, 19 de outubro de 2009. Rede de comunicação aberta. Transmissão gravada em 1 DVD (21 min), son., color.

KRISTEVA, J. Estrangeiros para nós mesmos. Trad. Vera Ribeiro, Rio de Janeiro: Jorge Zahar, 1994.

PÊCHEUX, M. Semântica e discurso: uma crítica à afirmação do óbvio. Trad. Eni Pulcinelli Orlandi et al. Campinas: Editora da UNICAMP, 1997.

REVUZ, C. A língua estrangeira entre o desejo de um outro lugar e o risco do exílio. Trad. Silvana Serrani. In: SIGNORINI, I. (org.) Língua(gem) e identidade: elementos para uma discussão no campo aplicado. Campinas: Mercado de Letras; São Paulo: Fapesp, 1998. p. 213 230 .

RICHARDS, J. C.; HULL, J.; PROCTOR, S. Interchange Third Edition. Teacher's Edition 1. New York: Cambridge University Press, 2005.

SANTOS, J.B.C. Discursividades e ensinância de línguas. In: BERTOLDO, E. S.; MUSSALIM, F. (Orgs.). Análise do Discurso. aspectos da discursividade no ensino. Goiânia: Trilhas Urbanas, 2006. p. 25-35.

Por uma teoria do Discurso Universitário Institucional. 2000. 236 f. Tese (Doutorado em Estudos Linguísticos) - Programa de Pós-Graduação em Estudos Linguísticos da Faculdade de Letras, Universidade Federal de Minas Gerais, Belo Horizonte, 2000.

SERRANI-INFANTE, S. Identidade e segundas línguas: as identificações no discurso. In: SIGNORINI, I. (org.) Língua(gem) e identidade: elementos para uma discussão no campo aplicado. Campinas: Mercado de Letras; São Paulo: Fapesp, 1998. p. 231-264.

. Formações discursivas e processos identificatórios na aquisição de línguas. DELTA, São Paulo, v. 13, n. 1, Fev, 1997. Disponível em $<$ http://www.scielo.br/scielo.php?script $=\quad$ sci_arttext\&pid=S0102-44501997000100004\& $\operatorname{lng}=$ en\&nrm=iso $>$. Acesso em 06 de janeiro de 2010, às $10 \mathrm{~h} 20 \mathrm{~min}$.

Artigo recebido em: 19.11.2012

Artigo aprovado em: 27.02.2013 